\title{
Pulsed-Field Gel Electrophoresis as a molecular tool for characterizing genomes of certain food-borne bacterial isolates - A Review
}

\author{
Partha Pal \\ Scottish Church College, 1 \& 3 Urquhart Square, Kolkata - 700006, Ind \\ E-mail address: parthapal_iicb@yahoo.co.in \\ The evolutionary transition from phenotypic to molecular ysis of in tir as disease in
}

\section{ABSTRACT} bacterial epidemiology led to the search for suitable approache to as ain genon c relatedness or heterogeneity between bacterial clinical isolates. Pulsed-fielo electr resis (PFGE) technique was developed for separating and analyzing long DNA fro sments of severa cgabases in alternating electric field. Comparison of electrophoresis profiles of restriction enzyme-digested genomic DNA from bacterial isolates has proved to be a useful epide ological too for genetic discrimination of bacterial strains, detection of genetic relatedness, to loca he source of outbreak and to monitor the spread of the microorganisms in endemic zone PFGE is ad as a gold standard method for typing of bacterial isolates because of the rema ndurance of this technique as a typing method for the last 20 years in molecular epidemiology. this preview the pros and cons of PFGE use in current molecular microbiological research are plored 2 n the context of determination of genome organization of certain food-borne bow isolates ausing infectious diseases in human beings.

Keywords: PFGE; Epidemiolo ; Restriction enzyme; Genome diversity

\section{INTRODUCRN}

In rece. rea muc of the rapid progress that is being made in molecular biology depends upon ability 10 separate, determine size and visualize DNA molecules. Gel electr pII sis (La 2., 1989) is one of the most commonly used separation techniques in the olecy ar biolosy laboratory. In conventional gel electrophoresis DNA molecules are separ matrix (i.e. agarose or polyacrylamide) under a static electric field. DNA fragmen rom 100 to $200 \mathrm{bp}$ up to $50 \mathrm{~kb}$ are routinely separated by this technique. In 1982 Schwartz o al., (Schwartz et al., 1982) introduced the concept that DNA molecules larger than $50 \mathrm{~kb}$ can be separated by using two alternating electric fields employed in Pulsed field gel electrophoresis (PFGE). Since that time, a number of instruments based on this principle have been developed, and the value of using pulsed fields has been demonstrated for separating DNAs from a few $\mathrm{kb}$ to over 10 megabase pairs $(\mathrm{Mb})$.

The development of PFGE has increased by two orders because of the magnitude of the size of DNA molecules that can be routinely fractionated and analyzed. This increase is of major importance in molecular biology because it simplifies many previously laborious investigations and makes possible many new ones. Its range of application spans all 
organisms (Gardiner, 1991) from bacteria and viruses to mammals (Smith et al., 1986). PFGE has shown excellent ability to separate small, natural linear chromosomal DNAs ranging in size from $50-\mathrm{kb}$ parasite microchromosomes to multimillion-bp yeast chromosomes. PFGE provides the means for the routine separation of fragments exceeding 6,000 kb (Gardiner, 1991; Steward et al., 1988; Maloy et al., 1994; Kaufmann and Pitt, 1994).

Therefore, PFGE separates DNAs from a few kilobase $(\mathrm{kb})$ to over 10 megabase pairs $(\mathrm{Mb})$ (Levene, 1992). The combined use of PFGE and restriction endonuclease digestion facilitated the determination of genome sizes as well as is the construction of physical maps of large numbers of bacterial isolates. The general applications of PFGE can be in the semaration of whole chromosomes, the large - scale restriction mapping of chromosome resons à in using DNA fragment purification as an initial step in cloning. The intrody on of $\mathrm{PF}$ techniques for separating large DNA molecules has had a stimulating effert on study chromosomal DNA molecules, genome structure and diversity. In thi review, use of PFGE in molecular microbiological analysis and the detection of ger nic he rogen, $y$ and relatedness of certain pathogenic food-borne bacterial isolates are $d$ cu.

\section{PFGE TYPES}

The pulsed electrophoresis effect has been utj TAFE, CHEF, OFAGE, PACE and rotating electro both large and small DNA molecules.

\section{1. Field-Inversion Gel Electrophoresis}

In 1986, Carle, Frank and Olson devel te a si pler system, FIGE, in which the two fields were placed $180^{\circ}$ apart (Can al.1986 Electrode polarity was reversed at intervals, with a longer forward than reve se pul time to cnerate a net forward sample migration. Net forward migration is achiever by res of forward to reverse pulse times to $3: 1$. To improve the resolutio 1 or the nds by FIGE, the duration of pulse times is increased progressively during a

This is called wito me ramping". By changing pulse durations continually during the course of an spriment, 5 has the advantages of straight lanes and simple equipment. FIGE is very opula for smally fragment separations and provides acceptable resolution up to 800 kiloba $(60,-150$ b).

\section{2. Ta erse-A rating Field Gel Electrophoresis (TAFE)}

This :nm of PGE allows separation of large DNA fragments in a simple, convenient forman TAFL, the gel is oriented vertically and a simple four-electrode array is placed not in the pla of the gel, but in front and at the back of it. Sample molecules are forced to zigzag thro gh the thickness of the gel, and all lanes experience the same effects, so the bands remain straight (Steward et al., 1988). As the molecules move down the gel, they are subjected to continual variations in field strength and reorientation angle, but to all lanes equally. TAFE has been used for the separation of fragments up to 1,600 kilobase fragments.

\section{3. Contour-Clamped Homogeneous Electric Fields (CHEF)}

The CHEF apparatus provides a more sophisticated solution to the distorting effects of both the edges of the chamber and the passive electrodes. CHEF has twenty-four point 
electrodes equally spaced around the hexagonal contour. CHEF uses an angle of reorientation of $120^{\circ}$ with gradiations of electropotential radiating from the positive to the negative pores. Molecules up to 7,000 kb can be separated by CHEF (Levene, 1992).

\section{4. Orthogonal-Field Alternation Gel Electrophoresis (OFAGE)}

A similar apparatus that used two nonhomogeneous electric fields was reported by Carle and Olson (Carle and Olson, 1984) in 1984. DNA molecules from 1,000 to 2,000 kb can be separated in OFAGE (Carle and Olson, 1984; Chu et al., 1986).

\section{5. Rotating Gel Electrophoresis (RGE)}

In England in 1987, Southern (Southern et al., 1987) described a navel GE syste that rotates the gel between two set angles while the electrodes are off $m$ KGE, alec $1 \mathrm{c}$ field is uniform and bands are straight because only one set of electro ss is RG akes it easy to perform time and voltage ramping. RGE uses a sing honeous field and changes the orientation of the electric field in relation to the gel by ontin ously and periodically rotating the gel. The DNA molecules migrat straight , due to the homogeneous fields, and DNA molecules from $50 \mathrm{~kb}, 6,00$ tb can be separated by adjusting the frequency of the gel rotation. In addition, gof of rotion can be easily altered simply by changing the angle of rotation (Gar Iner, 1991; Ziegl, and Vols, 1992).

\section{6. Programmable Autonomously-Controlled El $\operatorname{rodes}(\mathrm{P}$ CE)}

The PACE system can perform all pr pus pulsew switching regimens (i.e. FIGE, OFAGE, PHOGE, unidirectional pulsing), a the vonerate voltage clamped homogeneous static fields. The PACE system separates D A ragh nts from $100 \mathrm{bp}$ to over $6 \mathrm{Mb}$. The ability to alter the reorientation betwe the alternating fields permits an increased speed of separation for large D A $\mathrm{n}$ lecules. computer-driven system known as PACE, designed by Lai et al., (Lai e a 198 Lincondered to be the ultimate PFGE device. It is an extremely useful tool fo sudy, variavies such as pulse time, temperature, agarose concentration, voltage angles be fields affecting DNA migration in PFGE (Birren et
al., 1988).

\section{7. Pulsed-H omog neous Ory ogonal Field Gel Electrophoresis (PHOGE)}

The ma, dierenc between this instrument and other gel boxes with homogeneous electric solds is the reld reorientation angle is $90^{\circ}$. PHOGE uses a $90^{\circ}$ reorientation angl bu be DN colecules undergo four reorientations per cycle instead of two. This syo sep rates DNA fragments of up to $1 \mathrm{Mb}$ (Ziegler and Vols, 1992).

\section{PFGE \& PPLICATIONS}

The advent of PFGE techniques for the resolution of large DNA molecules has provided a new analysis approach for bacterial genomes (Dempsey et al., 1991). The PFGE of DNA fragments obtained using different enzymes is a powerful technique for quick resolution of the bacterial genome into a small number of large fragments. PFGE separated genomic DNA fragments obtained by using restriction endonucleases produce a discrete pattern of bands useful for the fingerprinting and physical mapping of the chromosome (Correia et al., 1994) as well as useful to establish the degree of relatedness among different strains of the same 
species (Correia et al., 1994). PFGE has proved to be an efficient method for genome size estimation and the construction of chromosomal maps, as well as being useful for the characterization of bacterial species (Basim et al., 1999; Churin et al., 1995; Roussel et al., 1994). PFGE technology has proven invaluable for the accurate estimation of genome size and in the construction of physical maps of a diverse range of prokaryotic organisms (Bourke et al., 1995; Pyle et al., 1990). This technique is a powerful tool for genome characterization and has led to the construction of the physical map of more than 180 bacterial chromosomes (Bourgeois et al., 1995).

PFGE will greatly facilitate the precise selection of large DNA fragments for alaning. REs which are specific for cutting infrequently occurring sequences are used to create DNA fragments which are then separated by PFGE. By blotting and hy idization fragments containing the desired gene are determined. This region is recomerea $\mathrm{m}$ the $\xi$ and cloned (Gardiner, 1991; Ziegler and Vols, 1992). This powerful molecular tool ws or easy isolation of the individual restriction fragments for further re iction apning gene insertion and functional gene mapping (Smith et al., 1988).

\section{ROLE OF PFGE IN THE STUDY OF GENOMES Q SEL TED PATHOGENIC BACTERIAL ISOLATES \\ 4. 1. Shigella spp.}

Shigella spp. is one of the most prevalent fo and water-borne pathogen which is consistently associated with dysentery and-nersistent (Ke et al., 2011). Shigellosis, the disease caused by Shigella, kills an estin 1 million people per year worldwide, $60 \%$

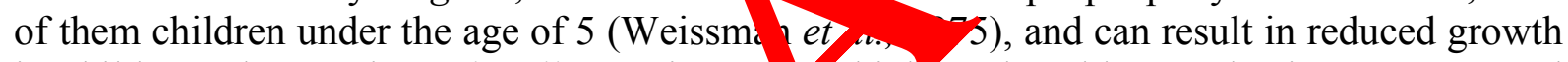
in children who survive. Shigella snecies app ar highy adaptable to selective pressure and have developed resistance to a ramb of anti icrobials with patterns of resistance varying temporally and geographicall ith a cimicrobin usage patterns (Rowe-Magnus and Mazel, 2002; Goh et al., 2010; C. bra, Fluit and Schmitz,2004). Resistant clones of Shigella have emerged j Argentina thite et al., 2001; Madiyarov et al., 2010; WHO 1987). Shigella flexneri ser y $\mathrm{p}$ variant, Aich emerged in China in 2001, has rapidly spread, including through A. Jentin. cording to recent report (Talukder et al., 2006), undergoing frequent serotyp switching an quiring resistance to multiple antimicrobials in the process (Nastasi et 1993 Recently study conducted in Argentina it was detected clusters of shigellosis of 1 health mportance, which have been confirmed by PFGE as consisting of closely ated c. a a informed local public health efforts (Vinas et al., 2013). Thus PFG - pro d to be seful tool for surveillance of the disease in an area. In a previous study bas on 5 CE indicated the evolutionary aspects where the type 7 and type 1 isolates of $S$. dysen. ve werc probably evolved from a same precursor, while the type 2 and $S$. flexneri type 2a orobably evolved and diversified from a common progenitor (Pal et al., 2013). PFGE anal,sis of certain strains of Shigella isolates in Bangladesh showed that S. sonnei biotype a strain was genetically more diverse than biotype strains of other Shigell isolates, and revealed that strains having different integron patterns belonged to different clusters Ud-Din et al., 2013). This finding is congruent with a previous study (Ranjbar et al., 2007).

\section{2. Salmonella spp.}

Salmonella Enteritidis remains a significant pathogen and a substantial threat to the food supply. It also represents one of the most genetically homogeneous serotypes of 
Salmonella, and certain clonal lineages remain intractable to differentiation by commonly used conventional subtyping methods (Fitzgerald et al., 2007; Sukhnanand et al., 2005; McQuiston et al., 2008; Xi et al., 2008; Hudson et al., 2001; Olsen et al., 1994; Zheng et al., 2007; Wise et al., 2009; Cebula et al., 2005). The unusual genetic homogeneity observed among certain lineages of $S$. Enteritidis strains remains intriguing. Recent population genetic studies suggest that most $S$. Enteritidis strains belong to a single multilocus genotype (Botteldoorn et al., 2010; Liu et al., 2011; Olson et al., 2007). A subpopulation of this clone was shown to associate more frequently with egg-related salmonellosis and clinical illness (Botteldoorn et al., 2010). In a study it was described the natural genetic variation within $S$. Enteritidis isolates associated with a widespread egg contamination event and ret ining pattern JEGX01.0004 and analyzed the comparative evolutionary genet within th important foodborne pathogen and several of its closest relatives. Based on b PCR a sequencing evidence, numerous studies have found little genetic variatio within $S$. erit dis (Olson et al., 2007; Guard et al., 2011; Shah et al., 2012; Tankouo-S djong al. 2 2 L). In a recent report on genomic diversity estimation for the $S$. nto s PFG Pattern JEGX01.0004 showed consistency with other diversity compari ons desch bet een two $S$. Enteritidis isolates of phage type 13 (Guard et al., 2011). Th otion was served both as SNP variation among 366 genes as well as the presence ana bsen numerous phages and plasmids among these close relatives. This genetic y/rau ity was do define the most variable genes and to assess population and phyl genetic evolutionary patterns for these important foodborne pathogens. This report on mparative genomics approach allowed investigators to cluster clinical isolates within the c ext of the r environmental source and farm isolates (Allard et al., 2013).

In one finding based on the results of by PFGE, MLVA, PCR, and sequencing, the Salmonella monophasic strains seemed ha Atained great homogeneity over the years. Another study carried out with some $S$ monella $(4,5,12$ :-) isolates from the United States and Spain concluded that ils s in most ikely represents multiple clones with distinct geographical distributions th nerg a throug independent deletion events (Soyer et al., 2009). This hypothesis wa pp a oy w...ther study and expanded the information given by Soyer et al., (Soyer l., 2009) a t Spanish monophasic strains, as they studied a larger number of strains an se 2010).

\section{3. Vibrio}

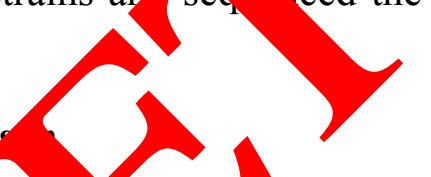

Vibrio cho is a am negative bacterium which lives freely in aquatic environment and aus choler $\mathrm{gh}$ et al., 2001). Cholera is endemic in many parts of the world, es $r$ ially he count ses which lack proper sanitation managements. In Malaysia cholera outbl a $V$. cholerae $\mathrm{O} 1$ serotype which occurs periodically (Vadivelu et al., 2000). ratio of distribution of $V$. cholerae $\mathrm{O} 139$ to $\mathrm{O} 1$ serogroups isolated from seafood from 19981999 was 14:1. Non-O1/non- O139 V. cholerae is also frequently isolated from seafood and water sources but has not been implicated in any major outbreaks (Elhadi et al., 2004; Chen et al., 2004). Although non-O1/non-O139 V. cholerae is not associated with any major outbreak, it has been reported to be responsible for sporadic cases of diarrhea (Nandi et al., 2000; Rivera et al., 2001; Faruque et al., 2004). The well-known genes associated with colonization are $c t x \mathrm{~A}$ and $t c p \mathrm{~A}$.

These genes are commonly found in $\mathrm{O} 1$ and $\mathrm{O} 139$ serogroups. Olivier et al., (Olivier et al.,2007) had reported that accessory toxins such as hemolysin and multifunctional autoprocessing RTX toxin in El Tor $V$. cholerae are involved in prolonged colonization 
without cholera toxin (CT) or toxin-coregulated pili (TCP). As these accessory virulence genes are commonly found in all serogroups of $V$. cholerae, it is of interest to investigate the involvement of these accessory virulence genes for prolonged colonization in other serogroups of $V$. cholerae. Molecular subtyping of pathogen is important for tracing a new or previously found virulent or multidrug-resistant clone. Genomic variation and epidemiological study for different serogroups of $V$. cholerae have been carried out using many DNA-fingerprinting tools. PFGE is the most common subtyping tool to define strains from outbreaks and from sporadic cases of cholera as it has the highest discriminatory ability (Chen et al., 2004). A combination approach of PFGE and MLVA analysis may yis-1-more information about the clonality of bacterial pathogens. PFGE is the most con anonly d subtyping method to determine the epidemiological relatedness of the strai In a curr study, the $23 \mathrm{O} 1$ strains were subtyped into 18 pulsotypes (Teh et al., 2a10). wever, different PFGE conditions were used by different researchers in the regi $\mathrm{n}$, direct c ari on was difficult. Adoption of a standardized PFGE protocol such as the "seNe FGE pocol proposed by CDC PulseNet, USA would greatly enhance inter hor comp ison and improve tracking of $V$. cholerae strains among the endemic cou ries in th gion (Teh et al., 2010).

In another study combination of both PFGE and LVA roaches for molecular typing to examine the bacterial genome by different orto result $\mathrm{com}$ each individual assay. Similar results were observed not only in PFG analysis but also in MLVA, though the components of some of the minor clusters differ Furthermse, even the oldest El Tor variants studied had already showed some genetic arsity an were divided into different minor clusters. These results suggested tha El Tor và ere related to various types of typical El Tor strains rather than classical the norians, and that the El Tor variante was likely to be caused by simultaneous or scu atial emergence and expansion of multiclones, and not by the prevalen of a cer in single clone (Morita et al., 2010).

\section{4. Escherechia coli}

STEC (Shiga toxin procucin. Tcherichia coli) consists of a group of food- and waterborne pathogens that $\mathrm{a}$ wn to cà Muman gastrointestinal diseases with a wide range of clinical spectra start g fro vatery and bloody diarrhea to hemorrhagic colitis (Gyles, 2007; Karmali, 2009) ocassionah licease symptoms result in the life-threatening, hemolytic uremic syndr me (US). Shi a toxins (Stx1 and Stx2) are the key virulence factors contributing the aevel ment of HUS. Although more than 200 different serotypes of STEC have bec olated $0157: \mathrm{H} 7$ has been the serotype most commonly associated with HUS 11 th Am Recent epidemiological studies have reported additional non-O157 ser coups includin O 26, O45, O91, O103, O104, O111, O113, O121, and O145, among STE were linked to severe human disease in the United States, Europe and countric Latin America (Brooks et al., 2005; Bettelheim, 2007; Caprioli et al., 2005; Mathusa el., 2010; Beutin and Martin, 2012).

PFGE, the current gold standard molecular method, for assessing STEC O157 genetic diversity (Swaminathan et al., 2001), primarily detects insertions and/or deletions within genomic regions specific to STEC O157 (Kudva et al., 2002). In one study it is reported that the PFGE based diversity pattern surpassed polymorphism-derived genotype diversity overall, although the PFGE polymorphisms are known to change between subcultures of the same strain of STEC O157:H7 (Iguchi et al., 2002) and that plasmid DNA migration within PFGE can be unpredictable (Barrett et al., 2006). This group identified ten different PFGE patterns in two or more strains with different polymorphism genotypes with 42 polymorphism-derived 
genotypes which have immediate potential to resolve genetically distinct STEC O157 strains comprising an outbreak investigation that may be indistinguishable by PFGE. They suggested future studies should be conducted that compare STEC O157 diversity assessed with the polymorphism-derived genotypes and PFGE using outbreak samples (Clawson et al., 2009).

In a recent study conducted on extended-spectrum beta-lactamase (ESBL)-producing $E$. coli from hospitals in Bangladesh phenotypic and molecular characterization of isolates using PFGE-typing revealed 26 different pulsotypes, but identical pulsotype showed 6 isolates of serotype O25:H4. Thus PFGE profile analysis showed heterogeneity among majority of isolates except for a few that could be clustered into a single PFGE type (Lina et al., 2014)

\section{DISCUSSION AND CONCLUSION}

PFGE has been used effectively as a molecular subtyping tool in utbrea invest rions and surveillance and has been used to infer genetic relatedness be ve olates o bacterial species (Shere et al., 1998; Swaminathan et al., 2001). PFGE ho been usc cor or a decade in epidemiologic studies of many eukaryotic and prokaryotic or isms and proved to be a robust typing method for investigations of food-ho ou aks and for hospital epidemiology. Alternative promising molecular methor oros for gro precision as well as higher efficiency for molecular epidemiologic an lyses of microbal pathogens include fluorescent amplified fragment length polymorp sms (Zhao et al., 2000) and DNA microarrays (Call et al., 2001; Salazar and Caetano olle 's, 1996). According to a report, for proper estimation of genetic relatednes between a. solates six or more restriction enzymes would be needed for investigatin nroper epidemiologic relationships using PFGE method (Davis et al., 2003).

The aim of this present review is to dem strate the usefulness of PFGE techniques as a tool to be used in identifying s arce clonal latedness and spread of bacterial isolates in hospitals and countries whe he $j$ lates have been recovered or encountered. Future applications for PFGE nic may clude protein separations and nucleic acid sequencing and studies DNA top vy This review will help current molecular biologists to assess the presen sta of this va able technique so that further modifications of this method may provis andis sable technology for genome study of organisms.

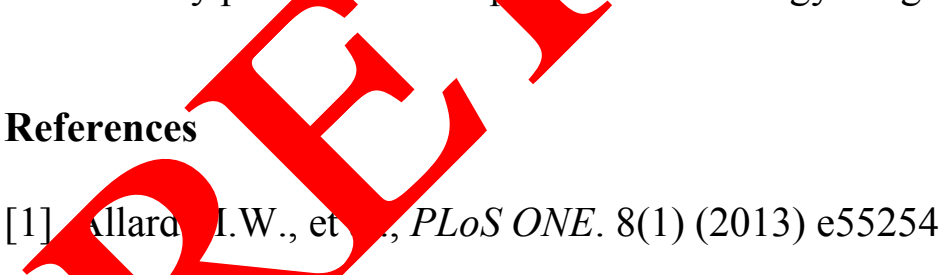

[2] D crner-Smidt P., Swaminathan B., Foodborne Pathogen Dis. 3 (2006) 20-31.

[3] Basıı Stall R.E., Minsavage J., Jones J., Phytopathology, 89 (1999) 1044-1049.

[4] Bettelkeim K.A., Crit Rev Microbiol 33 (2007) 67-87.

[5] Beutin L., Martin A., J Food Prot. 75 (2012) 408-418.

[6] Birren B.W., Lai E., Clark S.M., Houd L., Simon M.I., Nucl Acids Res. 16 (1988) 7563-7581.

[7] Botteldoorn N. et al., Zoonoses Public Health 57(5) (2010) 345-357.

[8] Bourgeois P.L., Lautier M., Berghe L.V.D., Gasson M.J., Ritzenthaler P., J. Bacteriology. 177 (1995) 2840-2850. 
[9] Bourke B., Sherman P., Louie H., Hani E., Islur P., Chan V.L., Microbiology 141 (1995) 2417-2424.

[10] Brooks J.T., Sowers E.G., Wells J.G., Greene K.D., Griffin P.M., Hoekstra R.M., Strockbine N.A., J Infect Dis. 192 (2005) 1422-1429.

[11] Call D.R., Brockman F.J., Chandler D.P., Int J Food Microbiol. 67 (2001) 71-80.

[12] Cambray G., Guerout A.M., Mazel D., Annu Rev Genet 44 (2010) 141-166.

[13] Caprioli A., Morabito S., Bruge`re H., Oswald E., Vet Res 36 (2005) 289-311.

[14] Carle G.F., Frank F., Olson M.V., Science. 232 (1986) 65-68.

[15] Carle G.F., Olson M.V., Nucl. Acids Res. 14 (1984) 5 647-5663.

[16] Cebula T.A., Brown E.W., Jackson S.A., Mammel M.K., Mukherje A., LeCla E Expert Rev Mol Diagn 5 (2005) 431-445.

[17] Chen C.-H., Shimada T., Elhadi N., Radu S., Nishibuchi M Microbiology 70 (4) (2004) 1964-1972.

[18] Chu G., Vollrath D., Davis R.W., Science 234 (1986) 82-1

[19] Churin Y.N., Shalak I.N., Borner T., Shestakov 3337-3343.

[20] Clawson M.L., Keen J.E., Smith T.P.L., Durso M., McDa eld T.G., Robert E., Mandrell R.E., Davis M.A., Bono J.L. Genome

[21] Correia A., Martin J.F., Castro J.M., M. Jur. 140 (1994) 2841-2847

[22] Davis M.A., Hancock D.D., Besser T.E., V.1 D.B., J Clin Microbiol. 41(5) (2003) 1843-1849.

[23] Dempsey J.A.F., Livake Mz hure A. snodgrass T.L., Cannon J.G., J. Bacteriology 173 (1991) 5476-54 [24] Elhadi N., Radu 5, Gen C.-H., Mibuchi M., Journal of Food Protection. 67(7)
(2004) 1469-1 5.

[25] Faruque S M., Chowdhur Y, Kamruzzaman M., Dziejman M., Rahman M.H., Sack D.A., Y G.B Yekalanos J.J., Proc Natl Acad Sci U.S.A. 101 ( 7) (2004) 2123-2128.

[26] Fitzgerald Collins M., van Duyne S., Mikoleit M., Brown T., et al., J Clin Microbiol 57) $33.32,4$.

[2, Vuit Schmitz F.J., Clin Microbiol Infect 10 (2004) 272-288.

[28] G. iner, K., Analytical Chemistry. 63 (1991) 658-665.

[29] Goh b., Chua D., Beck B., McKee M.L, Bhagwat A.A., Arch Microbiol 193 (2010) 179-185.

[30] Guard J., Morales C.A., Fedorka-Cray P., Gast R.K. BMC Res Notes. 26 (4) (2011) 369.

[31] Gyles C.L., J Anim Sci. 85 (2007) E45-62.

[32] Hudson C.R., Garcia M., Gast R.K., Maurer J.J., Avian Dis 45 (2001) 875-886.

[33] Iguchi A., Osawa R., Kawano J., Shimizu A., Terajima J., Watanabe H., J Clin Microbiol. 40 (2002) 3079-3081. 
[34] Karmali M.A., Kidney Int Suppl. (2009) S4-7.

[35] Kaufmann M.E., Pitt T.L., Methods in Practical Laboratory Bacteriology. 83 (1994)

[36] Ke X., Gu B., Pan S., Tong M., Arch Microbiol. 193 (2011) 767-774.

[37] Kudva I.T., Evans P.S., Perna N.T., Barrett T.J., Ausubel F.M., Blattner F.R., Calderwood S.B., J Bacteriol. 184 (2002) 1873-1879.

[38] Lai E., Birren B.W., Clark S.M., Simon M.I., Hood L., Biotechniques. 7(1989) 34-42.

[39] Laorden L. et al., J Clin Microbio. 48(12) (2010) 4563-4566.

[40] Levene S.D., Methods in Molecular Biology (1992) 345-365.

[41] Lina T.T. et al., PLoS ONE 9(10) (2014) e108735.

[42] Liu F., Kariyawasam S., Jayarao B.M., Barrangou R., Gerner-Smi „t P., N ibot E Knabel S.J., Dudley E.G., Appl Environ Microbiol. 77(13) (201, 520 +ว26.

[43] Madiyarov R.S., Bektemirov A.M., Ibadova G.A., Abdukh 1lova G. Khor Aev A.V., Bohidatta L., Sethabutr O., Mason C.J., Gut Pathog 2 (2 18.

[44] Maloy S.R., Cronan J.E. Jr., Freifelder D., Microbia netics. nes and Bartlett Publishers. Second Edition (1994) 45-47.

[45] Mathusa E.C., Chen Y., Enache E., Hontz L., f ood Prot. 73 (2010) 1721-1736.

[46] McQuiston J.R., Herrera-Leon S., Wertheim B. Doyle J Fields P.I., Tauxe R.V., Logsdon J.M. Jr., J Bacteriol 190 (20²) 7060-70

[47] Morita M., et al., Journal of Medical M. rovy 59 (2010) 708-712.

[48] Nandi B., Nandy R.K., Mukhomadhyay S, Nair G.B., Shimada T., Ghose A.C., Journal of Clinical Microbiology 3,(11) 000) 41 5,4151.

[49] Nastasi A., Pignato S. Ma in Amanco G., Epidemiol Infect 110 (1993) 23-30.

[50] Olivier V., Saly an Y., Fullne, satchell K.J., Infection and Immunity 75(10) (2007) 5043-5051.

[51] Olsen J.F., Sko M.N., Th , Afall E.J., Brown D.J., J Med Microbiol 40 (1994) 15-22.

[52] Olson A. ndrysia A.K., Tracz D.M., Guard-Bouldin J., Demczuk W., Ng L.K., M A., Jâ son F., Gilmour M.W., BMC Microbiol. 1(7) (2007) 87

Pal P Pal A., y yogi S.K., Ramamurthy T., Bhadra R.K., Indian J Med Res. 137 (2013)

[54] Py̆ E, Taylor T., Finch L.R., J. Bacteriology. 172 (1990) 7265-7268.

[55] Ranjbar R., Aleo A., Giammanco G.M., Dionisi A.M., Sadeghifard N., Mammina C., BMC Infect Dis. 7 (2007) 62.

[56] Rivera I.N.G., Chun J., Huq A., Sack R.B., Colwell R.R., Applied and Environmental Microbiology 67(6) (2001) 2421-2429.

[57] Roussel Y., Pebay M., Guedon G., Simonet J.M., Decaris B., J. Bacteriology 176 (1994) 7413-7422. 
[58] Rowe-Magnus D.A., Mazel D., Int J Med Microbiol 292 (2002) 115-125

[59] Salazar N.M., Caetano-Anolle 's G., Nucleic Acids Res. 24 (1996) 5056-5057.

[60] Schwartz D.C., Saffran W., Welsh J., Haas R., Goldenberg M., Cantor C.R., Cold Spring Harbor Symposia on Quantitative Biology, XLVII. (1982) 189-195.

[61] Shah D.H., Casavant C., Hawley Q., Addwebi T., Call D.R., Guard J., Foodborne Pathog Dis 9(3) (2012) 258-264.

[62] Shere J.A., Bartlett K.J., Kaspar C.W., Appl. Environ. Microbiol. 64 (1998) 1390-1399

[63] Singh D.V., Matte M.H., Matte G.R. Jiang S., Sabeena F., Shukla B.N., Sar yal S.C., Huq A., Colwell R.R., Applied and Environmental Microbiology 67 (2) 1) 910-92

[64] Smith C.J., Coote J.G., Parton R.R., J. Gen. Microbiol. 1432 (1986) -005-26,

[65] Smith C.L., Klco S.R., Cantor C.R., Washington D.C., IRL Pres a ford 1988) -72.

[66] Southern E.M., Anand R., Brown W.R., Fletcher D.S., Nucl ads 15 (19 ת) 5925-5943.

[67] Soyer Y., et al, J Clin Microbiol. 47 (2009) 3546-355

[68] Steward G., Furst A., Avdalovic N., Biotechniqu s 6 (1988) 68- $>$

[69] Sukhnanand S., Alcaine S., Warnick L.D., Su -L., Hof J., Graver M.P., McDonough P., Boor K.J., Wiedmann M., J Clin Microbiol. (2005) 36 88-3698.

[70] Swaminathan B., Barrett T.J., Hunter Tauxe Inerg Infect Dis.7 (2001) 382-389.

[71] Talukder K.A., Khajanchi B.K., Islam M \, Dutta D.K., Islam Z., Khan S.I., Nair G.B., Sack D.A., Epidemiol Infect -006) 1. 49-1256.

[72] Tankouo-Sandjong B., K. H. Aallace /., FEMS Micro Let 331(2) (2012) 165-175

[73] Teh C.S.J., Chua K 1., Mons L. Journal of Biomedicine and Biotechnology (2010) $1-7$.

[74] Ud-Din A.I.M et al., oS ONE 8(12) (2013) e82601.

[75] Vadively S., Iy L., Kshat ya B.M., Puthucheary S.D., Epidemiology and Infection. 124(1) 00) $20-30$.

[76] Vim M.R., q1., P LoS Negl Trop Dis. 7(12) (2013) e2521.

Weis han J.B., Jangorosa E.J., Schmerler A., Marier R.L., Lewis J.N. Lancet 1 (1975)

[78] Wh P.A., McIver C.J., Rawlinson W.D., Antimicrob Agents Chemother 45 (2001) $2658-061$.

[79] WHO, Geneva, Switzerland. (1987) 9-20.

[80] Wise M.G., Siragusa G.R., Plumblee J., Healy M., Cray P.J., Seal B.S., J Microbiol Methods 76 (2009) 18-24.

[81] Xi M., Zheng J., Zhao S., Brown E.W., Meng J., J Food Prot 71 (2008) 2067-2072.

[82] Zhao S., Mitchell S.E., Meng J., Kresovich S., Doyle M., Dean R.E., Casa A., Weller J., Microb Infect. 2 (2000)107-113. 
[83] Zheng J., Keys C.E., Zhao S., Meng J., Brown E.W., Emerg Infect Dis 13 (2007) 1932-1935.

[84] Ziegler A., Vols A., Methods in Molecular Biology (1992) 63-72.

( Received 23 October 2014; accepted 31 October 2014 )

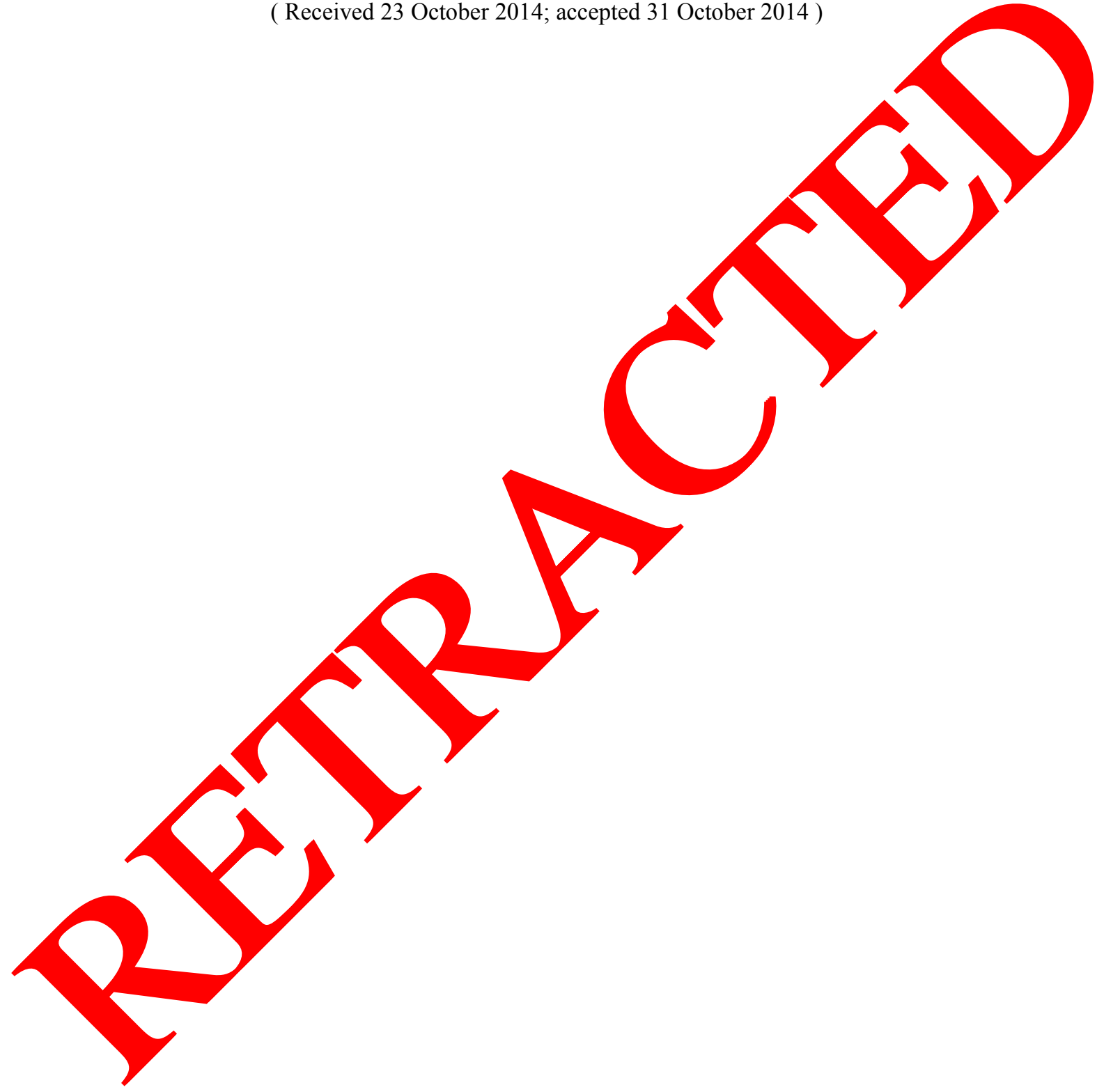

